\title{
Correction to: Comparative chloroplast genomes of Prunus subgenus Cerasus (Rosaceae): insights into sequence variations and phylogenetic relationships
}

\author{
Jiawen Yan ${ }^{1}$. Jianhui $\mathrm{Li}^{1} \cdot \mathrm{Lin}_{\mathrm{Yu}}{ }^{1} \cdot$ Wenfu Bai ${ }^{1} \cdot$ Dongling Nie $^{1} \cdot$ Ying Xiong $^{1} \cdot$ Sizheng $\mathrm{Wu}^{1}$ \\ Published online: 18 December 2021 \\ ๑) Springer-Verlag GmbH Germany, part of Springer Nature 2021
}

Correction to: Tree Genetics \& Genomes (2021) 17: 50

https://doi.org/10.1007/s11295-021-01533-8

Tables 1, 2 and 3 are not formatted correctly in the published proof.

The Original article has been corrected.

Publisher's note Springer Nature remains neutral with regard to jurisdictional claims in published maps and institutional affiliations.

The original article can be found online at https://doi.org/10.1007/ s11295-021-01533-8.

Sizheng Wu

loutus001@163.com

Jiawen Yan

yanjw200709@126.com

Jianhui Li

jianlee86@hotmail.com

1 Hunan Botanical Garden, Changsha 410116, China 